\title{
Kualitas Sumber Air Tangkiling yang Digunakan sebagai Air Baku Air Minum Isi Ulang dari Aspek Uji MPN Total Coliform
}

\author{
Kamaliah \\ Program Studi Teknik Lingkungan Universitas Muhammadiyah Palangkaraya \\ email: kamaliah@umpalangkaraya.ac.id
}

\begin{abstract}
ABSTRAK. Kualitas sumber air Tangkiling yang digunakan sebagai air baku air minum isi ulang dari aspek uji MPN Total Coliform yang bertujuan untuk mengetahui kualitas sumber air Tangkiling dan jumlah perkiraan terdekat bakteri Total Coliform pada sumber air tangkiling yang digunakan sebagai air baku air minum isi ulang. Metode yang digunakan adalah metode deskriptif yaitu suatu metode yang dilakukan dengan tujuan untuk membuat gambaran atau deskripsi tentang suatu keadaan secara objektif. Sampel dalam penelitian ini adalah sumber air Tangkiling yang digunakan sebagai air baku air minum isi ulang dengan teknik pengambilan sampel yang digunakan pada peneliti adalah sampling jenuh. Pemeriksaan Uji MPN Total Coliform yang dilakukan, didapatkan hasil yang tidak memenuhi syarat batas maksimal Indeks MPN yaitu sebanyak 2 sampel air (20\%) sedangkan sebagian besar memiliki hasil yang memenuhi syarat nilai Indeks MPN yaitu sebanyak 5 sampel air (80\%).
\end{abstract}

Kata kunci : MPN total Coliform, sumber air baku, air minum

\section{PENDAHULUAN}

Air merupakan kebutuhan utama bagi kehidupan. Kebutuhan akan air disuatu daerah akan selalu mengalami kecenderungan naik seiring dengan pertambahan penduduk. Sedangkan air sendiri berkurang dari segi kualitas, dan juga kontinuitas.

Sumber air baku memegang peranan penting dalam industri air minum. Air baku merupakan awal dari suatu proses dalam penyediaan dan pengolahan air bersih.

Berdasar SNI 6773:2008 tentang Spesifikasi unit paket instalasi pengolahan air dan SNI 6774:2008 tentang Tata cara perencanaan unit paket instalasi pengolahan air pada bagian Istilah dan Definisi yang disebut dengan air baku untuk air minum adalah : Standar kualitas air adalah baku mutu yang ditetapkan berdasarkan sifat-sifat fisik, kimia, radioaktif, maupun bakteriologis yang menunjukan persyaratan kualitas air tersebut.

Sumber air baku yang digunakan oleh Depot Air Minum Isi Ulang (DAMIU) yang tidak sesuai dengan ketentuan atau peraturan yang berlaku dapat mengakibatkan kualitas air minum tidak memenuhi standar kualitas air minum yang ditentukan karena apabila kualitas air minum tidak memenuhi syarat khususnya kualitas bakteriologis yang akan menibulkan gangguan kesehatan.

Salah satu bakteri yang dapat menimbulkan gangguan kesehatan adalah Bakteri Coliform. Bakteri Coliform adalah golongan bakteri intensital, yaitu hidup didalam pencernaan manusia. Contoh bakteri Coliform adalah , Escherichia coli. Jadi, Coliform adalah indikator kualitas air.

Menurut peraturan menteri kesehatan Republik Indonesia (PERMENKES RI) 
nomor 416 tahun 1990, tentang syarat-syarat dan pengawasan kualitas air, persyaratan mikrobiologi pada air bersih yaitu bakteri coliform dan Coli tinja pada setiap $100 \mathrm{ml}$ sampel air yang dinyatakan dengan 10 MPN/100 ml sampel.

Metode pengujian yang digunakan dalam penelitian ini adalah Most Probable Number (MPN) atau Jumlah Perkiraan Terdekat (JPT) metode tabung ganda. Dalam penelitian ini peneliti hanya menggunakan uji kualitatif Coliform terdiri dari uji dugaan (presumptive test) dan uji penegasan (Confirmative test).

\section{METODE PENELITIAN}

Metode penelitian ini merupakan metode penelitian Deskriptif. Penelitian deskriptif adalah suatu metode penelitian yang dilakukan dengan tujuan utama untuk membuat gambaran atau deskripsi tentang suatu keadaan secara objektif (Sibagariang.dkk,2010:62).

Pada penelitian ini bertujuan untuk mengetahui kualitas sumber air baku tangkiling yang digunakan sebagai air baku air isi ulang dari aspek uji MPN Total coliform. Lokasi Penelitian ini dilakukan di Laboratorium Fakultas Ilmu Kesehatan Universitas Muhammadiyah Palangka Raya. Penelitian ini dilakukan mulai dari permohonan ijin tempat penelitian hingga pelaksaan penelitian, dimulai dari bulan Juli sampai September 2017.

Populasi adalah keseluruhan dari unit di dalam pengamatan yang akan dilakukan. Populasi yang digunakan dalam penelitian ini adalah sumber air baku Tangkiling yang digunakan sebagai Air Baku Air Minum Isi Ulang. (Hastono, 2008). Sampel sebagian dari populasi yang nilai/karakteristiknya diukur dan dipakai untuk meduga karakteristik dari populasi.

Sampel pada penelitian ini adalah total populasi dari air yang berasal dari sumber air Tangkiling yang digunakan sebagai Air Baku Air Minum Isi Ulang.

Teknik penarikan sampel yang digunakan adalah sampling jenuh. Sampling jenuh merupakan teknik penentuan sampel bila semua anggota populasi digunakan sebagai sampel. (Sugiyono, 2001:61). Dalam penelitian ini peneliti menggunakan beberapa teknik pengumpulan data, yaitu sebagai berikut:

1. Observasi (Pengamatan langsung)

2. Mengukur indeks MPN (Most Probable Number) Total Coliform dengan menggunakan metode MPN.

\section{Alat \& Bahan}

Alat \& Bahan yang dipakai untuk mendapatkan data dalam penelitian ini adalah sebagai berikut :

1. Alat :

Tabung reaksi (16 x 160 mm),Rak tabung reaksi,Tabung Durham, Lampu spirtus, Jarum Ose, Timbangan analitik, Kompor listrik, Erllen Mayer, Oven, Autoclaf, Inkubator, Bola hisap, Botol sampel, Kapas, Pipet ukur, Alumunium foil, Kertas Coklat

2. Bahan :

Media Lactose Broth (LBSS dan LBDS), Briliant Green Lactose Bile Broth (BGLB), Aquadest

3. Sampel

Sumber air Baku Tangkiling yang digunakan sebagai air baku air Minum Isi Ulang

\section{Prosedur Kerja}

Adapun prosedur kerja adalah sebagai berikut :

1. Pembuatan Media

a. Pembuatan Media LBSS (Lactose Broth Single Strength)

1) Timbang media Lactose Broth sebanyak 13 gram

2) Lalu, masukkan ke dalam Erlenmeyer, Lalu ukur pH 7,0

3) Kemudian, tambahkan aquadest sebanyak 1 liter,

4) Panaskan sampai larut sempurna diatas Hot Plate

5) Kemudian, masukkan kedalam tabung reaksi 16 x $160 \mathrm{~mm}$ 
sebanyak $10 \mathrm{ml}$ (lengkap dengan tabung durham)

6) Lalu sterilkan pada autoclave dengan suhu $121^{\circ} \mathrm{C}$ selama 15 20menit.

b. Pembuatan Media LBDS (Lactose Broth Double Strength)

1) Untuk pembuatan media LBDS, timbang media Lactose Broth sebanyak $3 \mathrm{x}$ dari media LBSS,

2) Masukkan ke dalam Erlenmeyer, Lalu ukur pH 7,0

3) Tambahkan aquadest sebanyak 1 liter,

4) Panaskan sampai larut sempurna diatas Hot Plate

5) Masukkan kedalam tabung reaksi 16 x $160 \mathrm{~mm}$ sebanyak 5 $\mathrm{ml}$ (lengkap dengan tabung durham)

6) Lalu sterilkan pada autoclave dengan suhu $121^{\circ} \mathrm{C}$ selama 15 20menit.

c. Pembuatan Media BGLB (Brilliant Green Lactose Broth)

1) Timbang media sebanyak 40 gram

2) Masukkan ke dalam Erlenmayer, Lalu ukur pH 7,0

3) Tambahkan aquadest sebanyak 1 liter,

4) Kemudian masukkan kedalam tabung reaksi 16 x $160 \mathrm{~mm}$ sebanyak $5 \mathrm{ml}$ (lengkap dengan tabung durham)

5) Lalu sterilkan pada autoclave dengan suhu $121^{\circ} \mathrm{C}$ selama 15 20menit.

d. Uji Kualitas Media (Control positif dan negative)

1) Pembuatan Standar Mc Farland 0,5

(a) Mencampurkan $0,05 \mathrm{ml}$ larutan $\quad 1,175 \%$ barium klorida $(\mathrm{BaCl} 2)$ dan 9,95 ml larutan $1 \%$ Asam Sulfat $\left(\mathrm{H}_{2} \mathrm{SO}_{4}\right)$ dalam tabung reaksi.

(b) Tutup tabung reaksi dan simpan.

2) Pembuatan suspensi bakteri

E.Coli dan Staphylococus aureus

(a) Kultur bakteri yang di inginkan pada media agar miring

(b) Inkubasi pada suhu $37^{\circ} \mathrm{C}$ selama 24 jam

(c) Masukkan $\mathrm{NaCl}$ fisiologis steril/akuades steril kedalam tabung reaksi steril sesuai dengan volume yang di inginkan

(d) Ambil 1 ose biakan bakteri, campurkan kedalam bakteri, dan sesuaikan dengan standar Mc Farland 0,5

3) Pengujian kualitas media

(a) Media yang telah dibuat dan disterilkan (LBDS,LBSS dan BGLB) di tambahkan suspense bakteri E.Coli dan Staphylococus aureus sebanyak $2 \mathrm{ml}$

(b) Lalu di inkubasi pada suhu $37^{\circ} \mathrm{C}$ selama $1 \times 24 \mathrm{jam}$

Catatan Apabila kualitas media baik maka pada media control positif akan terbentuk gelembung udara dan keruhan. Dan pada media control negative hanya akan terbentuk keruhan saja.

2. Pengambilan Sampel

a. Menyiapkan alat dan bahan, seperti botol sampel steril, spritus, dan kertas label.

b. Membuka penutup botol sampel lalu melewatkan api pada mulut botol sampel. 
c. Memasukkan sampel air sampai kirakira $200 \mathrm{ml}$.

d. Melewatkan lagi api pada mulut botol sampel.

e. Menutup rapat botol sampel dan memberikan label dengan mencantumkan Nama sampel, Nama petugas pengambilan sampel, Tanggal dan jam pengambilan sampel, dan Tempat pengambilan sampel.

f. Menyimpan sampel pada kotak sampel yang sudah disediakan.

3. Pemeriksaan MPN Coliform

a. Tes Penduga

Tes penduga atau tes perkiraan dengan menggunakan metode MPN ragam II (5-5-5) 15 tabung, adalah sebagai berikut :

1) Sampel air yang telah dihomogenkan dengan cara membolak balik botol sampel sebanyak 3x .

2) Dipipet menggunakan pipet steril

3) Dipipet $10 \mathrm{ml}$ sampel ke dalam tabung yang bersisi LBDS $5 \mathrm{ml}$ sebanyak 5 tabung

4) Dipipet $1 \mathrm{ml}$ sampel ke dalam tabung yang berisi LBSS $10 \mathrm{ml}$ sebanyak 5 tabung

5) Di pipet $0,1 \mathrm{ml}$ sampel ke dalam tabung yang berisi LBSS $10 \mathrm{ml}$ sebanyak 5 tabung

6) Kemudian diinkubasi pada suhu $37^{\circ} \mathrm{C}$ selama $1 \times 24$ jam. Apabila dalam 24 jam belum ada pertumbuhan maka diteruskan selama 48 jam.

Hasil :

(a) Positif (+) : Jika terjadi kekeruhan pada media dan terbentuk gas pada tabung durham

(b) Negatif (-) : hanya terjadi kekeruhan dan tanpa gas.

b. Tes Penegasan (Confirmative Test)
Test ini menggunakan media Brilliant Green Lactose Broth (BGLB), media ini akan menghambat pertumbuhan bakteri gram positif dan sebaliknya yaitu menstimulasi pertumbuhan bakteri gram negatif seperti Coliform.

1) Hasil yang positif pada tes perkiraan dilanjutkan ke tes penegasan.

2) Ambil 1-2 ose LB positif, lalu ditanam ke media BGLB.

3) 1 tabung LB positif di tanam pada 1 seri BGLB.

4) $\mathrm{BGLB}$ di Inkubasi pada suhu $37^{\circ} \mathrm{C}$ selama 24-48 jam untuk pemeriksaan bakteri Total Coliform.

5) Untuk mendapatkan jumlah MPN Coliform, dengan dasar hasil pencatatan dari tabung BGLB yang positif. Baca hasil pada tabel MPN.

\section{Teknik Analisis Data}

Teknik analisis data yang digunakan adalah metode persentase, yaitu setelah semua data terkumpul data tersebut diolah secara manual, maka hasil penelitian disajikan dalam bentuk table dengan mengumpulkan data, mengelompokkan data, memasukkan data dalam table dan disajikan dalam bentuk narasi.

Caranya yaitu dengan membagi frekuensi kejadian (f) dengan populasi (n) dan dikalikan $100 \%$ dengan rumus berikut.

$$
p=\frac{f}{n} x 100 \%
$$

Keterangan :

$f$ : Jumlah angka kejadian

$n$ : Seluruh sampel yang akan disajikan

$p$ : Persentase

\section{HASIL DAN PEMBAHASAN \\ Hasil Penelitian}

1. Hasil pemeriksaan Coliform pada Sumber air Tangkiling yang digunakan sebagai air baku air minum isi ulang 
Tabel 1. Hasil Uji Perkiraan Sumber Air Tangkiling Yang di gunakan sebagai air baku air minum isi ulang menggunakan media LBSS dan LBDS

\begin{tabular}{|c|c|c|c|c|c|c|c|c|c|c|c|c|c|c|c|c|}
\hline \multirow[b]{2}{*}{ Kode } & \multicolumn{15}{|c|}{ MPN/ml sampel (ml) } & \multirow[b]{2}{*}{ Jumlah } \\
\hline & 10 & 10 & 10 & 10 & 10 & 1 & 1 & 1 & 1 & 1 & 0,1 & 0,1 & 0,1 & 0,1 & 0,1 & \\
\hline 1 & + & + & + & + & + & + & + & 0 & 0 & 0 & 0 & 0 & + & 0 & 0 & $\begin{array}{lll}5 / 5 & 2 / 5 & 1 / 5\end{array}$ \\
\hline 2 & + & 0 & 0 & + & 0 & 0 & 0 & 0 & 0 & 0 & 0 & 0 & 0 & 0 & 0 & $\begin{array}{lll}2 / 5 & 0 / 5 & 0 / 5\end{array}$ \\
\hline 3 & + & 0 & + & + & 0 & 0 & 0 & 0 & 0 & 0 & 0 & 0 & 0 & 0 & 0 & $\begin{array}{lll}3 / 5 & 0 / 5 & 0 / 5\end{array}$ \\
\hline 4 & + & 0 & 0 & 0 & 0 & 0 & 0 & 0 & 0 & 0 & 0 & 0 & 0 & 0 & 0 & $\begin{array}{lll}1 / 5 & 0 / 5 & 0 / 5\end{array}$ \\
\hline 5 & 0 & + & 0 & 0 & 0 & 0 & 0 & 0 & 0 & 0 & 0 & 0 & 0 & 0 & 0 & $\begin{array}{lll}1 / 5 & 0 / 5 & 0 / 5\end{array}$ \\
\hline 6 & + & + & 0 & + & 0 & 0 & 0 & 0 & 0 & 0 & 0 & 0 & 0 & 0 & 0 & $\begin{array}{lll}3 / 5 & 0 / 5 & 0 / 5\end{array}$ \\
\hline 7 & + & + & + & + & + & 0 & 0 & 0 & 0 & 0 & 0 & 0 & 0 & 0 & 0 & $\begin{array}{lll}5 / 5 & 0 / 5 & 0 / 5\end{array}$ \\
\hline
\end{tabular}

Keterangan:

$(+)=$ Positif (ditandai dengan terbentuknya gelembung dan terjadi kekeruhan)

$0=$ Negatif (ditandai dengan tidak terbentuknya gelembung dan kekeruhan)

Tabel 2. Hasil Uji Penegasan Sumber Air Tangkiling Yang di gunakan sebagai air baku air minum isi ulang menggunakan media BGLB

\begin{tabular}{|c|c|c|c|c|c|c|c|c|c|c|c|c|c|c|c|c|}
\hline \multirow{2}{*}{ Kode } & \multicolumn{15}{|c|}{ MPN/ml sampel (ml) } & \multirow{2}{*}{ Jumlah } \\
\hline & 10 & 10 & 10 & 10 & 10 & 1 & 1 & 1 & 1 & 1 & 0,1 & 0,1 & 0,1 & 0,1 & 0,1 & \\
\hline 1 & + & + & + & + & + & 0 & + & 0 & 0 & 0 & 0 & 0 & 0 & 0 & 0 & $\begin{array}{lll}5 / 5 & 1 / 5 & 0 / 5 \\
\end{array}$ \\
\hline 2 & + & 0 & 0 & 0 & 0 & 0 & 0 & 0 & 0 & 0 & 0 & 0 & 0 & 0 & 0 & $1 / 5 \quad 0 / 5 \quad 0 / 5$ \\
\hline 3 & + & 0 & + & + & 0 & 0 & 0 & 0 & 0 & 0 & 0 & 0 & 0 & 0 & 0 & $\begin{array}{lll}3 / 5 & 0 / 5 & 0 / 5\end{array}$ \\
\hline 4 & 0 & 0 & 0 & 0 & 0 & 0 & 0 & 0 & 0 & 0 & 0 & 0 & 0 & 0 & 0 & $\begin{array}{lll}0 / 5 & 0 / 5 & 0 / 5\end{array}$ \\
\hline 5 & 0 & 0 & 0 & 0 & 0 & 0 & 0 & 0 & 0 & 0 & 0 & 0 & 0 & 0 & 0 & $\begin{array}{lll}0 / 5 & 0 / 5 & 0 / 5\end{array}$ \\
\hline 6 & 0 & + & 0 & 0 & 0 & 0 & 0 & 0 & 0 & 0 & 0 & 0 & 0 & 0 & 0 & $\begin{array}{lll}1 / 5 & 0 / 5 & 0 / 5\end{array}$ \\
\hline 7 & + & + & + & + & + & 0 & 0 & 0 & 0 & 0 & 0 & 0 & 0 & 0 & 0 & $\begin{array}{llll}5 / 5 & 0 / 5 & 0 / 5\end{array}$ \\
\hline
\end{tabular}

Keterangan:

$(+)=$ Positif (ditandai dengan terbentuknya gelembung dan terjadi kekeruhan)

$0=$ Negatif (ditandai dengan tidak terbentuknya gelembung dan kekeruhan

Tabel 3. Gambaran MPN Total Coliform pada Sumber air Tangkiling yang digunakan sebagai air baku air minum isi ulang dari aspek Uji MPN Total Coliform

\begin{tabular}{|c|c|c|c|c|}
\hline \multirow{2}{*}{ Kode } & \multicolumn{2}{|c|}{ Hasil Pemeriksaan } & \multirow{2}{*}{$\begin{array}{l}\text { Indeks MPN / } \\
100 \mathrm{ml} \text { sampel }\end{array}$} & \multirow[b]{2}{*}{ Keterangan } \\
\hline & Uji Perkiraan & Uji Penegasan & & \\
\hline 1 & $5 / 52 / 51 / 5$ & 510 & 110 & Tidak Memenuhi Syarat \\
\hline 2 & $2 / 50 / 50 / 5$ & 100 & 2 & Memenuhi Syarat \\
\hline 3 & $3 / 50 / 50 / 5$ & 300 & 8 & Memenuhi Syarat \\
\hline 4 & $1 / 50 / 50 / 5$ & 000 & 0 & Memenuhi Syarat \\
\hline 5 & $1 / 50 / 50 / 5$ & 000 & 0 & Memenuhi Syarat \\
\hline 6 & $3 / 50 / 50 / 5$ & 100 & 2 & Memenuhi Syarat \\
\hline 7 & $5 / 50 / 50 / 5$ & 500 & 70 & Tidak Memenuhi Syarat \\
\hline
\end{tabular}

Keterangan : Dari hasil MPN Total Coliform pada 7 sampel sumber air Tangkiling yang digunakan sebagai air baku air minum isi ulang didapatkan hasil 2 sampel yang memiliki indeks diatas batas maksimum yaitu sampel nomor 1 dan 7, hal ini ditandai dengan indeks MPN/100ml sampel nomor 1 adalah 110 dan sampel nomor 7 adalah 70 .

2. Presentase Kualitas Mikrobiologi pada Sumber Air Tangkiling yang digunakan sebagai air baku air minum isi ulang

Tabel 4. Presentase Kualitas Mikrobiologi pada Sumber Air Tangkiling yang digunakan sebagai air baku air minum isi ulang

\begin{tabular}{ccc}
\hline \multirow{2}{*}{ Variabel } & \multicolumn{2}{c}{ Jumlah } \\
\cline { 2 - 3 } & $\mathrm{N}$ & $\%$ \\
\hline Tidak Memenuhi Syarat & 2 & 20 \\
Memenuhi Syarat & 5 & 80 \\
Total & 7 & $100 \%$ \\
\hline
\end{tabular}

Tabel di atas menunjukkan presentase kualitas mikrobiologi pada sampel air. Hasil Menunjukkan sampel air 20\% tidak memenuhi syarat, dan $80 \%$ memenuhi syarat. 


\section{Pembahasan}

Most Probable Number (MPN) adalah suatu metode numerasi mikroorganisme yang menggunakan data dari hasil pertumbuhan mikroorganisme pada medium cair spesifik. Dalam seri tabung yang ditanam dari sampel padat atau cair yang ditanam berdasarkan jumlah sampel atau diencerkan menurut tingkat seri tabungnya, sehingga dihasilkan kisaran jumlah mikroorganisme yang diuji dalam nilai MPN/satuan volume atau massa sampel. Prinsip utama dari metode ini adalah mengencerkan sampel sampai tingkat tertentu sehingga didapatkan konsentrasi mikroorganisme yang pas atau sesuai, dan jika ditanam dalam tabung menghasilkan frekuensi pertumbuhan tabung positif, kadang-kadang tapi tak selalu. Semakin besar jumlah sampel yang dimasukkan (semakin rendah pengenceran yang dilakukkan) maka semakin sering tabung positif yang muncul. Semakin kecil jumlah sampel yang dimasukkan (semakin tinggi pengenceran yang dilakukan) maka semakin jarang tabung positif yang akan muncul. Jumlah sampel atau pengenceran yang baik adalah yang menghasilkan tabung positif, kadang-kadang tapi tidak selalu. Semua tabung positif yang dihasilkan sangat bergantung dengan probabilitas sel yang terambil oleh pipet saat memasukkan kedalam media. Oleh karena itu homogenisasi sangat mempengaruhi metode ini.

Metode MPN terbagi menjadi beberapa ragam yaitu ragam 7 tabung, 9 tabung dan 15 tabung. Pemilihan ragam ini tergantung pada jenis sampel yang akan diuji berdasarkan tingkat kerapatan bakteri dalam sampel tersebut. Untuk sampel air yang sudah diolah seperti air minum menggunakan ragam 7 tabung karena diperkirakan kerapatan bakterinya rendah. Sedangkan untuk sampel air yng belmdiolah seperti air sungai atau air bersih menggunakan ragam 9 taung atau 15 tabung karena diperkirakan kerapatan bakterinya tinggi.

Pemeriksaan mikrobiologi metode MPN dibagi menjadi 2 tahap yaitu uji perkiraan dan uji penegasan, menggunakan media laktosa yang menjadi sumber bahan makanan bakteri untuk berkembang biak. Pada tahap perkiraan pada penelitian ini didapatkan hasil berikut.

Tabel 5. Hasil Uji Perkiraan Sumber Air Tangkiling Yang di gunakan sebagai air baku air minum isi ulang menggunakan media LBSS dan LBDS

\begin{tabular}{|c|c|c|c|c|c|c|c|c|c|c|c|c|c|c|c|c|}
\hline \multirow{2}{*}{ Kode } & \multicolumn{15}{|c|}{ MPN/ml sampel (ml) } & \multirow{2}{*}{ Jumlah } \\
\hline & 10 & 10 & 10 & 10 & 10 & 1 & 1 & 1 & 1 & 1 & 0,1 & 0,1 & 0,1 & 0,1 & 0,1 & \\
\hline 1 & + & + & + & + & + & + & + & 0 & 0 & 0 & 0 & 0 & + & 0 & 0 & $\begin{array}{lll}5 / 5 & 2 / 5 & 1 / 5\end{array}$ \\
\hline 2 & + & 0 & 0 & + & 0 & 0 & 0 & 0 & 0 & 0 & 0 & 0 & 0 & 0 & 0 & $2 / 5 \quad 0 / 5 \quad 0 / 5$ \\
\hline 3 & + & 0 & + & + & 0 & 0 & 0 & 0 & 0 & 0 & 0 & 0 & 0 & 0 & 0 & $\begin{array}{llll}3 / 5 & 0 / 5 & 0 / 5\end{array}$ \\
\hline 4 & + & 0 & 0 & 0 & 0 & 0 & 0 & 0 & 0 & 0 & 0 & 0 & 0 & 0 & 0 & $\begin{array}{lll}1 / 5 & 0 / 5 & 0 / 5\end{array}$ \\
\hline 5 & 0 & + & 0 & 0 & 0 & 0 & 0 & 0 & 0 & 0 & 0 & 0 & 0 & 0 & 0 & $\begin{array}{llll}1 / 5 & 0 / 5 & 0 / 5\end{array}$ \\
\hline 6 & + & + & 0 & + & 0 & 0 & 0 & 0 & 0 & 0 & 0 & 0 & 0 & 0 & 0 & $\begin{array}{llll}3 / 5 & 0 / 5 & 0 / 5\end{array}$ \\
\hline 7 & + & + & + & + & + & 0 & 0 & 0 & 0 & 0 & 0 & 0 & 0 & 0 & 0 & $\begin{array}{llll}5 / 5 & 0 / 5 & 0 / 5\end{array}$ \\
\hline
\end{tabular}

Keterangan:

$(+)=$ Positif (ditandai dengan terbentuknya gelembung dan terjadi kekeruhan)

$0=$ Negatif (ditandai dengan tidak terbentuknya gelembung dan kekeruhan)

Pada penelitian ini, 5 dari 7 sampel positif ditumbuhi oleh bakteri yang ditandai dengan terbentuknya gelembung udara dan keruhan. Pada tahap perkiraan keberadaan Coliform masih dalam tingkat probabilitas rendah atau masih dalam dugaan, karena beberapa jenis bakteri lain juga tumbuh dalam tahap ini. Oleh karena itu hasil positif dalam tahap perkiraan dilanjutkan ke tahap penegasan dengan bantuan media selektif differensial untuk memastikan keberadaab bakteri Coliform. Pada tahap penegasan untuk uji Total Coliform diinkubasi pada suhu $37^{\circ} \mathrm{C}$, karena pada suhu ini bakteri lain tidak dapat tumbuh. Pada penelitian ini didapatkan hasil : 
Tabel 6. Hasil Uji Penegasan Sumber Air Tangkiling Yang di gunakan sebagai air baku air minum isi ulang menggunakan media BGLB

\begin{tabular}{|c|c|c|c|c|c|c|c|c|c|c|c|c|c|c|c|c|}
\hline \multirow[b]{2}{*}{ Kode } & \multicolumn{15}{|c|}{ MPN/ml sampel (ml) } & \multirow[b]{2}{*}{ Jumlah } \\
\hline & 10 & 10 & 10 & 10 & 10 & 1 & 1 & 1 & 1 & 1 & 0,1 & 0,1 & 0,1 & 0,1 & 0,1 & \\
\hline 1 & + & + & + & + & + & 0 & + & 0 & 0 & 0 & 0 & 0 & 0 & 0 & 0 & $\begin{array}{lll}5 / 5 & 1 / 5 & 0 / 5\end{array}$ \\
\hline 2 & + & 0 & 0 & 0 & 0 & 0 & 0 & 0 & 0 & 0 & 0 & 0 & 0 & 0 & 0 & $\begin{array}{lll}1 / 5 & 0 / 5 & 0 / 5\end{array}$ \\
\hline 3 & + & 0 & + & + & 0 & 0 & 0 & 0 & 0 & 0 & 0 & 0 & 0 & 0 & 0 & $\begin{array}{lll}3 / 5 & 0 / 5 & 0 / 5\end{array}$ \\
\hline 4 & 0 & 0 & 0 & 0 & 0 & 0 & 0 & 0 & 0 & 0 & 0 & 0 & 0 & 0 & 0 & $\begin{array}{lll}0 / 5 & 0 / 5 & 0 / 5\end{array}$ \\
\hline 5 & 0 & 0 & 0 & 0 & 0 & 0 & 0 & 0 & 0 & 0 & 0 & 0 & 0 & 0 & 0 & $\begin{array}{lll}0 / 5 & 0 / 5 & 0 / 5\end{array}$ \\
\hline 6 & 0 & + & 0 & 0 & 0 & 0 & 0 & 0 & 0 & 0 & 0 & 0 & 0 & 0 & 0 & $\begin{array}{lll}1 / 5 & 0 / 5 & 0 / 5\end{array}$ \\
\hline 7 & + & + & + & + & + & 0 & 0 & 0 & 0 & 0 & 0 & 0 & 0 & 0 & 0 & $\begin{array}{llll}5 / 5 & 0 / 5 & 0 / 5\end{array}$ \\
\hline
\end{tabular}

Keterangan:

$(+)=$ Positif (ditandai dengan terbentuknya gelembung dan terjadi kekeruhan)

$0=$ Negatif (ditandai dengan tidak terbentuknya gelembung dan kekeruhan

Hasil positif ditandai dengan terbentuknya kekeruhan dan gas karena bakteri memfermentasikan laktosa menjadi asam laktat. Kekeruhan disebabkan oleh meningkatnya asam sehingga komponen laktosa menggumpal. Gumpalan inilah yang menjadikan hasil keruh. Sedangkan gas berasal dari hasil fermentasi laktosa membentuk gas karbondioksida. Gas inilah yang nantinya akan terperangkap dalam tabung durham yang dipasang terbalik. Secara garis besar reaksi fermentasinya adalah sebagai berikut:

$$
\begin{array}{lll}
\mathrm{C}_{12} \mathrm{H}_{22} \mathrm{O}_{11} \stackrel{2 \mathrm{NAD+}}{\longrightarrow} & \mathrm{C}_{6} \mathrm{H}_{12} \mathrm{O}_{6} \stackrel{2 \mathrm{NAD+}}{\longrightarrow} & \mathrm{C}_{3} \mathrm{H}_{6} \mathrm{O}_{3}+\mathrm{CO}_{2} \\
\text { (Laktosa) } & \text { (Glukosa) } & \begin{array}{l}
\text { (Asam laktat } \\
\text { Karbndioksida) }
\end{array}+
\end{array}
$$

Jumlah tabung yang positif disesuaikan dengan tabel MPN sehingga diperoleh indeks MPN Total Coliform. Hasil penelitian ini dapat digambarkan sebagai berikut:

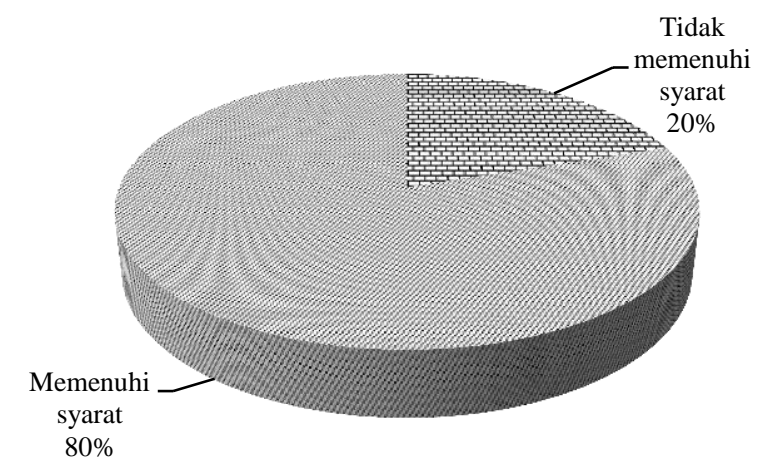

Gambar 4.1 gambar Presentase Kualitas Sumber Air Tangkiling yang digunakan sebagai air baku air minum isi ulang
Diagram diatas menunjukkan bahwa presentase air tidak memenuhi syarat sebesar 20\%, hasil ini mengindikasikan bahwa air tersebut tercemar oleh bakteri Coliform. Pengambilan sampel dilakukan pada lokasi sumber air Tangkiling yang berbeda yaitu 7 lokasi, yang mana digunakan sebagai air baku air minum isi ulang, yang memiliki kualitas 2 sampel yang tidak memenuhi syarat. Hal ini dimungkinkan karena tercemarnya sumber air yang diakibatkan oleh letak yang cukup berdekatan dengan pemukiman penduduk, tepi jalan, dan selokan, keadaan seperti ini tentu tidak tepat, karena dapat mempengaruhi kualitas sumber air.

Sampel yang tercemar bakteri Total Coliform dimungkinkan berasal dari limbah yang dihasilkan oleh manusia yang tinggal disekitar lokasi yang meresap melalui tanah dan mencemari sumber air.

Pencemaran air oleh bakteri Total Coliform sangat berbahaya, karena bakteri golongan ini mengandung bakteri E.coli yang merupakan penyebab utama penyakit diare. Penyakit diare sangat berbahaya karena dapat menyebabkan kehilangan cairan dengan jumlah yang sangat besar. Jika terus menerus kehilangan cairan, maka dapat mengakibatkan kematian. Oleh karena itu sangat perlu untuk dilakukan pengawasan kualitas air yang digunakan.

\section{KESIMPULAN}

Berdasarkan hasil penelitian yang telah dilakukan terhadap sumber air Tangkiling yang digunakan sebagai air baku air minum isi ulang dari aspek Uji MPN Total Coliform, dapat diambil kesimpulan sebagai berikut : 
Dari pemeriksaan Uji MPN Total Coliform yang dilakukan, didapatkan hasil yang tidak memenuhi syarat batas maksimal Indeks MPN yaitu sebanyak 2 sampel air (20\%) sedangkan sebagian besar memiliki hasil yang memenuhi syarat nilai Indeks MPN yaitu sebanyak 5 sampel air (80\%).

\section{SARAN}

Untuk masyarakat lebih waspada dan memilih serta memperhatikan sumber air agar tidak terkontaminasi oleh cemaran air yang dapat menyebabkan terjadi masalah kesehatan seperti Diare.

\section{DAFTAR PUSTAKA}

Arthur dalam Isti, Analisis Mikrobiologi pada

Makanan. Yogyakarta, Fakultas Pertanian Universitas Sebelas Maret Surakarta, Pdf.(/;/;p. diakses tanggal 1 Januari 2017)

Amsyari, F., 1996, Membangun Lingkungan Sehat Menyambut 50 Tahun Indonesia Merdeka, Airlangga University Press, Surabaya.

Athena, 2004, Usaha Depot Air Minum Isi Ulang
Dinas Kesehatan Kota Palangka Raya. Kalteng, 2016, Data Kasus Diare di Kota Palangka Raya Tahun 2016.

Effendi, H., 2003, Telaah Kualitas Air bagi Pengelolaan Sumber Daya dan Lingkungan Perairan, Kanisius, Yogyakarta.

Novel, S., 2010, Praktikum Mikrobiologi Dasar, Trans Info Media, Jakarta.

Peraturan Menteri Kesehatan Nomor : 416/MEN.KES/PER/IX/1990 Tentang Syarat Syarat Dan Pengawaan Kualitas Air.Menteri Kesehatan Republik Indonesia.(http://web.ipb.ac.id/ tml_ats p (sitasi 11 mei 2017)

PerPem RI No. 82 Tahun 2001 tentang Pengelolaan Kualitas Air Dan Pengendalian Pencemaran Air. Jakarta

Suriawiria, U., 2008, Mikrobiologi Air, Penerbit P.T Alumni, Bandung

Staf Pengajar Fakultas Kedokteran UI, 1994, Buku Ajar: Mikrobiologi Kedokteran, Jakarta.

SNI 6773:2008 tentang Spesifikasi unit paket instalasi pengolahan air

SNI 6774:2008 tentang Tata cara perencanaan unit paket instalasi pengolahan air

Waluyo, L., 2008, Mikrobiologi Lingkungan, UMM Press, Malang. 